\title{
Paraneoplastic Hypercalcemia Secondary to Canine Mammary Tumors
}

\author{
Talita Mariana Morata Raposo-Ferreira', Giovanna Rossi Varallo', Sabryna Gouveia Calazans², \\ Paulo Cesar Jark', Rosana da Cruz Lino Salvador', Mirela Tinucci-Costa', \\ Andrigo Barboza De Nardi', Geovanni Dantas Cassali ${ }^{3}$ \& Renée Laufer-Amorim ${ }^{4}$
}

\begin{abstract}
Background: Paraneoplastic syndromes are complexes symptom that occur at a distinct site from the primary tumor or its metastasis by the production of hormone by the tissue in which the tumor appears. Paraneoplastic hypercalcemia is associated with an abnormal elevation of serum calcium levels and the mainly tumor related to this syndrome in canine is lymphoma, anal sac apocrine gland adenocarcinoma and multiple myeloma. In mammary tumors, the most frequent tumor that affect female dogs, this syndrome was also observed. The aims of this study were to evaluate serum calcium levels in female dogs with malignant mammary tumors and correlate calcium levels with clinicopathological parameters. Materials, Methods \& Results: It was evaluated fifty-one female dogs with mammary carcinomas (simple carcinomas and carcinoma in mixed tumors) for serum calcium levels using colorimetric test. Clinical-histopathological data as spray status, pseudopregnancy, tumor size, ulceration, clinical staging, histopathological type and tumor grade were also evaluated in association with serum calcium levels. All dogs were treated with unilateral mastectomy. It was observed that 18 animals (35\%) had calcium serum levels increased $(>11.5 \mathrm{mg} / \mathrm{dL})$ and $56 \%(10 / 18$ cases $)$ of these animals had serum calcium levels higher than $12 \mathrm{mg} / \mathrm{dL}$. All dogs with hypercalcemia were asymptomatic, including two female dogs that presented the highest levels $(13.43 \mathrm{mg} / \mathrm{dL}$ and $14.28 \mathrm{mg} / \mathrm{dL})$. Hypercalcemia of malignancy was related to mammary carcinomas after the exclusion of other causes of hypercalcemia through laboratory tests (complete blood count and serum biochemistry) and abdominal ultrasound. No correlation was verified between the corrected serum calcium values with clinical and histopathological parameters evaluated.

Discussion: In this study, it was observed a high incidence of paraneoplastic hypercalcemia associated with canine mammary tumors (35\%). In humans, this syndrome is related in up to $10 \%$ of all patients with advanced cancer and with worse prognosis. The most frequent clinical signs of hypercalcemia are nonspecific and can be confused with other diseases, such as polyuria, polydipsia, anorexia, constipation, lethargy and weakness. The treatment of this syndrome is based on tumor resection and when necessary other treatments can be performed with fluid containing $0.9 \%$ sodium chloride, furosemide, prednisolone and calcitonin. Patients with asymptomatic or mildly symptomatic hypercalcemia (calcium levels $<12 \mathrm{mg} /$ dL) do not require immediate treatment. Clinical signs occur more frequently with serum calcium levels higher than 15 $\mathrm{mg} / \mathrm{dL}$. Calcium levels higher than $18 \mathrm{mg} / \mathrm{dL}$ are considered a medical emergency and the clinical signs observed are trigger seizures, cardiac arrhythmia, acute renal failure and death. Most animals of this study presented mild hypercalcemia, that could justify the absence of clinical signs related to this syndrome, and the treatment for this syndrome was the tumor removal. The high serum calcium levels did not show correlation with more aggressive tumors and poorer prognosis, conditions evaluated by histological type, tumor grade and clinical stage. The evaluation of serum calcium levels is an important clinical test to be done in female dogs with mammary tumors, besides to be an affordable and technically simple test. The clinical signs related to this syndrome are nonspecific and may be confused with other diseases commonly observed in older dogs. The data suggest that there are no correlation between serum calcium levels with aggressiveness of canine mammary tumors and with other clinical features.
\end{abstract}

Keywords: calcium, carcinoma, dog, mammary gland, paraneoplastic syndrome.

${ }^{1}$ Department of Veterinary Clinic and Surgery, UNESP, Jaboticabal, SP, Brazil. ${ }^{2}$ Department of Surgery in Small Animals, University of Franca (UNIFRAN), Franca, SP. ${ }^{3}$ Department of General Pathology, Institute of Biological Sciences, Federal University of Minas Gerais (UFMG), Belo Horizonte, MG, Brazil. ${ }^{4}$ Department of Veterinary Clinic, UNESP, Botucatu, SP. CORRESPONDENCE: R. Laufer-Amorim [renee@ fmvz.unesp.br - Tel.: +55 (14) 3811-6293]. Departamento de Clínica Veterinária, Faculdade de Medicina Veterinária e Zootecina, Universidade Estadual Paulista, Rubião Junior s/n ${ }^{\circ}$. Caixa Postal 560. CEP 18618.000 Botucatu, SP, Brazil. 


\section{INTRODUCTION}

Paraneoplastic hypercalcemia or hypercalcemia of malignancy $(\mathrm{HM})$ is a paraneoplastic syndrome associated with an abnormal elevation of serum calcium. It is normally associated with the secretion of parathyroid hormone-related protein (PTH-rP) by the neoplasm. Other causes of HM include the following: ectopic production of parathormone (PTH), extensive lytic bone metastases, primary hyperparathyroidism, tumorassociated prostaglandins (PGE1/2), interleukin-1beta, transforming growth factor-beta and receptor activator of nuclear factor kappa beta ligand [2,10,16,20,23,24].

Neoplasia is the most common cause of hypercalcemia in dogs [2,5]. Lymphoma, mainly cranial mediastinum, is the major tumor that causes HM, followed by anal sac apocrine gland adenocarcinoma and multiple myeloma $[2,8,16]$.

Other tumors associated with HM in dogs was thyroid carcinoma, bone tumors, thymoma, squamous cell carcinoma, melanoma, primary lung tumors, chronic lymphocytic leukemia, renal angiomyxoma, parathyroid gland and mammary carcinomas $[2,8,11,12,14,16,18,19]$.

The aims of this study were to evaluate serum calcium levels in female dogs with mammary carcinomas and its association with clinical and histopathological parameters.

\section{MATERIALS AND METHODS}

Animals

Fifty-one female dogs examined at the Veterinary Oncology Service of FCAV/UNESP, Jaboticabal, SP, Brazil with mammary carcinoma had serum calcium levels evaluated by colorimetric test. The mean age of the animals was $10.24 \pm 2.48$ years. The treatment of all patients consisted of unilateral mastectomy.

Clinical-histopathological data as spray status, pseudopregnancy, tumor size, ulceration, clinical staging, histopathological type and tumor grade were evaluated in association with serum calcium levels. Clinical staging was obtained by the evaluation of tumor size, nodal status and metastasis according to a modified WHO clinical staging system, stage I (T1NOM0), stage II (T2N0M0), stage III (T3N0M0), stage IV (TanyN1M0), and stage V (TanyNanyM1) [21]. The animals received 3-dimensional thoracic radiographs and abdominal ultrasound to assess metastatic disease.
Complete blood count and serum biochemistry (creatinine, urea, alanine aminotransferase and alkaline phosphatase) analyses results were within the normal range for the species.

\section{Histopathological analysis}

For histopathological evaluations mammary gland tumors were fixed in $10 \%$ buffered formalin and then embedded in paraffin. The tissues were cut into $5 \mu \mathrm{m}$ thick sections and stained with hematoxylin and eosin (HE). All cases were reviewed and re-classified independently by two veterinary pathologists. The histological classification was performed according to Cassali et al. [3] and tumor grade into grade I, grade II and grade III [6].

\section{Evaluation of serum calcium}

The total serum calcium levels were evaluated by the colorimetric method (Labtest). The results were corrected by albumin levels according to the formula: Calcium - Albumin + 3.5 and the values are reported in $\mathrm{mg} / \mathrm{dL}$ [2]. The reference value range was 8.0 to 11.5 $\mathrm{mg} / \mathrm{dL}$ [1]. The calcium measurement was performed before surgery.

\section{Data and statistical analysis}

The analysis of serum calcium values and the association with clinical and histopathological parameters were performed by nonparametric Kruskal-Wallis or Mann-Whitney U- tests. The results were considered to be statistically significant at $P<0.05$. GraphPad Prism 5 software was used for all of the statistical analysis (GraphPad Software Inc., La Jolla, CA).

\section{RESULTS}

Hypercalcemia was observed in 18 animals $(35 \%)$ with calcium serum levels higher than 11.5 $\mathrm{mg} / \mathrm{dL}$. Moreover, $56 \%$ (10/18 cases) of the female dogs with hypercalcemia had serum calcium levels higher than $12 \mathrm{mg} / \mathrm{dL}$ (Table 1). However, all dogs with hypercalcemia were asymptomatic. Other causes of hypercalcemia were excluded by laboratory tests (complete blood count and serum biochemistry) and abdominal ultrasound.

The frequency of histopathological types is represented in Table 2. According to the tumor grade, $74 \%$ of cases were grade I, $20 \%$ were grade II and $6 \%$ were grade III. No correlation was verified between the corrected serum calcium value with clinical and 
histopathological parameters (Figures 1 and 2, respectively, $P>0.05)$. The tumors were divided into simple carcinomas and carcinomas in mixed tumor to histopathological analysis. Serum calcium mean values associated with clinicopathological features are presented in Table 3.
A

$$
\mathrm{p}=\mathbf{0 . 9 8 1 9}
$$
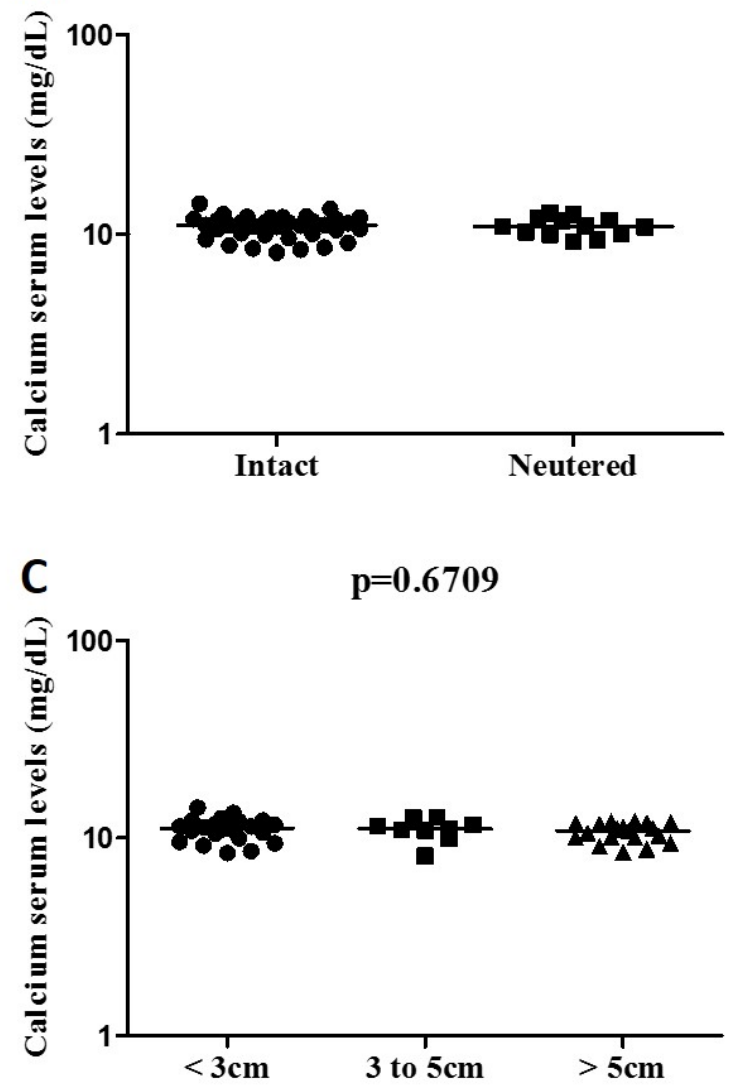

B $\quad \mathrm{p}=\mathbf{0 . 7 8 9 9}$
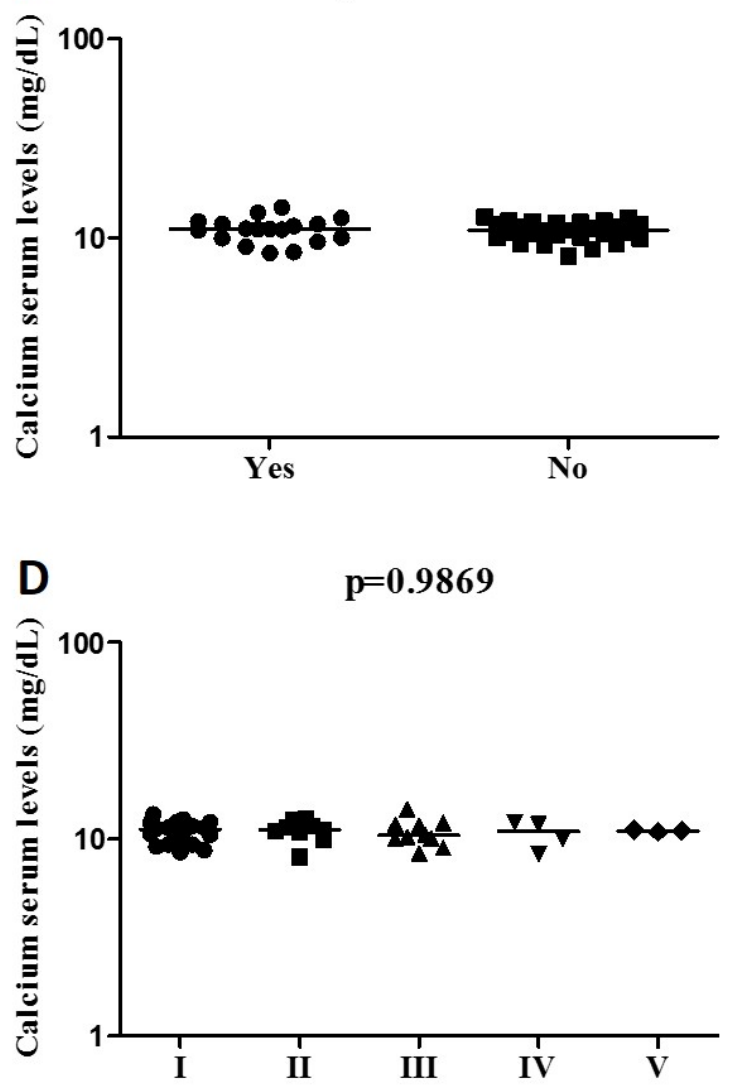

Figure 1. Corrected calcium serum level analysis according to clinical parameters. A)- Reproductive status. B)- Pseudopregnancy. C)- Tumor size. D)Tumor stage. [The bars indicate the median value].
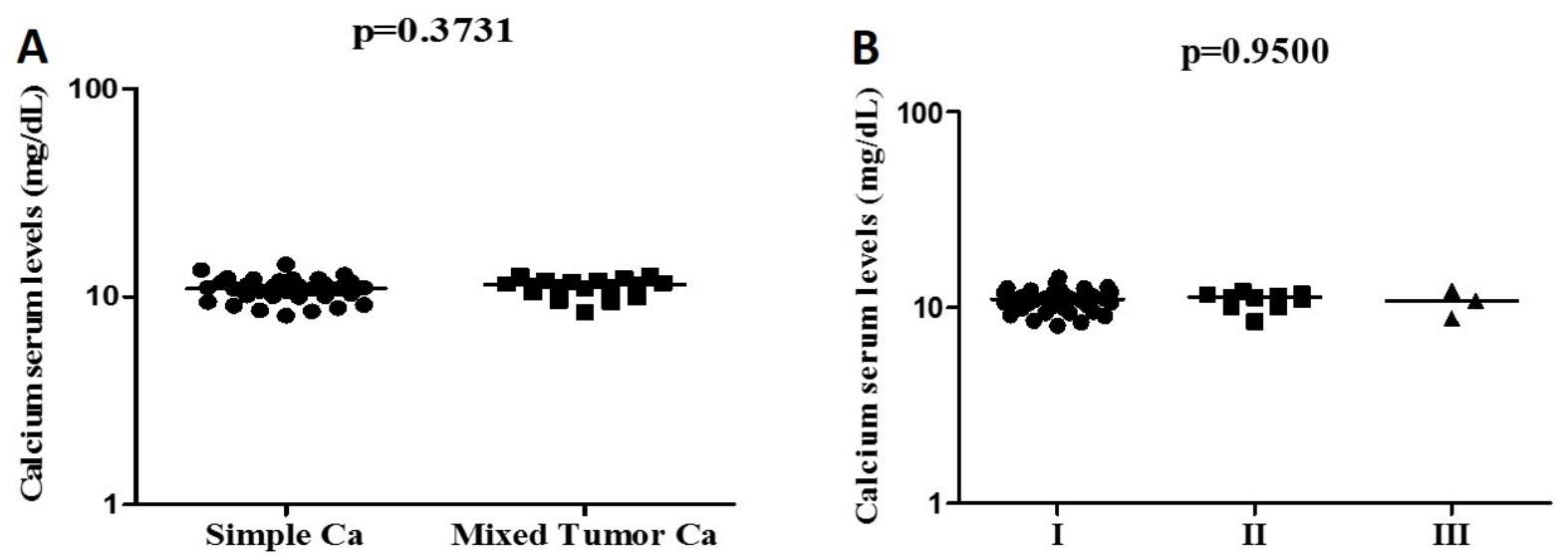

Figure 2. Evaluation of calcium serum levels with histopathological features. A)- Histopathological types. B)- Tumor grade. [The bars indicate the median value. $\mathrm{Ca}=$ carcinoma]. 
Table 1. Clinical parameters and total serum calcium values from female dogs with mammary tumors.

\begin{tabular}{|c|c|c|c|c|c|}
\hline Patient & $\begin{array}{c}\text { Reproductive } \\
\text { status }\end{array}$ & Pseudopregnancy & Contraceptive use & $\begin{array}{c}\text { Tumor } \\
\text { stage }\end{array}$ & $\begin{array}{c}\mathrm{Ca}^{*} \\
(\mathrm{mg} / \mathrm{dL})\end{array}$ \\
\hline 1 & Intact & Yes & No & III & 9.06 \\
\hline 2 & Intact & No & No & IV & 10.07 \\
\hline 3 & Intact & Yes & No & III & 12.16 \\
\hline 4 & Intact & Yes & No & II & 12.60 \\
\hline 5 & Intact & No & No & $\mathrm{I}$ & 10.53 \\
\hline 6 & Intact & $* *$ & $* *$ & I & 11.48 \\
\hline 7 & Intact & No & No & I & 8.60 \\
\hline 8 & Neutered & Yes & No & I & 9.98 \\
\hline 9 & Intact & Yes & No & IV & 8.40 \\
\hline 10 & Neutered & No & No & III & 10.31 \\
\hline 11 & Intact & No & No & II & 8.12 \\
\hline 12 & Intact & No & No & $\mathrm{I}$ & 11.46 \\
\hline 13 & Intact & No & No & I & 9.42 \\
\hline 14 & Intact & No & No & I & 10.94 \\
\hline 15 & Intact & No & No & II & 9.95 \\
\hline 16 & Intact & Yes & No & I & 9.57 \\
\hline 17 & Intact & Yes & No & II & 11.52 \\
\hline 18 & Intact & No & No & I & 10.66 \\
\hline 19 & Intact & No & No & III & 10.63 \\
\hline 20 & Intact & No & No & III & 10.13 \\
\hline 21 & Intact & No & Yes & I & 12.21 \\
\hline 22 & Intact & No & No & IV & 12.19 \\
\hline 23 & Intact & Yes & No & III & 11.77 \\
\hline 24 & Intact & $* *$ & $* *$ & I & 11.10 \\
\hline 25 & Intact & No & No & I & 11.36 \\
\hline 26 & Intact & No & No & I & 8.8 \\
\hline 27 & Neutered & No & No & I & 9.42 \\
\hline 28 & Neutered & No & No & I & 11.99 \\
\hline 29 & Neutered & No & No & II & 11.64 \\
\hline 30 & Neutered & No & No & I & 9.16 \\
\hline 31 & Intact & Yes & No & III & 10.06 \\
\hline 32 & Intact & No & No & I & 11.67 \\
\hline 33 & Intact & Yes & Yes & I & 13.43 \\
\hline 34 & Intact & Yes & No & III & 14.28 \\
\hline 35 & Intact & Yes & No & $\mathrm{V}$ & 11.15 \\
\hline 36 & Neutered & No & No & II & 12.75 \\
\hline 37 & Intact & No & No & III & 11.93 \\
\hline 38 & Neutered & No & No & II & 10.96 \\
\hline 39 & Intact & Yes & No & III & 8.50 \\
\hline 40 & Intact & $* *$ & $* *$ & IV & 11.91 \\
\hline 41 & Intact & No & No & II & 11.14 \\
\hline 42 & Intact & $* *$ & $* *$ & II & 12.15 \\
\hline 43 & Intact & $* *$ & $* *$ & I & 12.28 \\
\hline 44 & Intact & Yes & No & V & 11.05 \\
\hline 45 & Neutered & $* *$ & $* *$ & I & 11.76 \\
\hline 46 & Neutered & No & No & I & 12.63 \\
\hline 47 & Neutered & Yes & No & I & 10.91 \\
\hline 48 & Neutered & Yes & No & II & 11.04 \\
\hline 49 & Intact & $* *$ & $* *$ & I & 11.26 \\
\hline 50 & Intact & $* *$ & $* *$ & I & 11.37 \\
\hline 51 & Intact & $* *$ & $* *$ & $\mathrm{~V}$ & 10.92 \\
\hline
\end{tabular}

*Calcium serum levels corrected by albumin. **Information not provided by the owner. 
Table 2. Histopathological diagnosis from mammary gland tumors $(\mathrm{n}=51)$.

\begin{tabular}{cc}
\hline Histopathological type & Frequency \\
\hline Anaplastic carcinoma & $1(2 \%)$ \\
Micropapillary carcinoma & $1(2 \%)$ \\
Carcinoma in situ & $2(4 \%)$ \\
Papillary carcinoma & $2(4 \%)$ \\
Solid carcinoma & $4(8 \%)$ \\
Carcinoma in mixed tumor & $17(33 \%)$ \\
Tubular carcinoma & $24(47 \%)$ \\
\hline
\end{tabular}

Table 3. Mean value of corrected serum calcium associated with histopathological and clinical parameters.

\begin{tabular}{|c|c|}
\hline Variable & Corrected serum calcium mean values (mg/dL) \\
\hline \multicolumn{2}{|l|}{ Histopathological type } \\
\hline Carcinoma in mixed tumor & $11.12 \pm 1.150$ \\
\hline Simple carcinoma & $10.85 \pm 1.438$ \\
\hline \multicolumn{2}{|l|}{ Tumor grade } \\
\hline I & $11.02 \pm 1.396$ \\
\hline II & $10.86 \pm 1.06790$ \\
\hline III & $11.03 \pm 1.60$ \\
\hline \multicolumn{2}{|l|}{ Tumor Size } \\
\hline$<3 \mathrm{~cm}$ & $11 \pm 1.436$ \\
\hline 3 to $5 \mathrm{~cm}$ & $11.08 \pm 1.399$ \\
\hline$>5 \mathrm{~cm}$ & $10.77 \pm 1.159$ \\
\hline \multicolumn{2}{|l|}{ Tumor Stage } \\
\hline I & $10.97 \pm 1.261$ \\
\hline II & $11.08 \pm 1.399$ \\
\hline III & $10.88 \pm 1.690$ \\
\hline IV & $10.64 \pm 1.766$ \\
\hline $\mathrm{V}$ & $11.04 \pm 0.1153$ \\
\hline \multicolumn{2}{|l|}{ Reproductive State } \\
\hline Intact & $10.90 \pm 1.433$ \\
\hline Neutered & $10.05 \pm 1.171$ \\
\hline \multicolumn{2}{|l|}{ Pseudopregnancy } \\
\hline Absence & $10.77 \pm 1.279$ \\
\hline
\end{tabular}

\section{DISCUSSION}

The evaluation of serum calcium levels in this study showed a high incidence of this syndrome associated with canine mammary tumors $(35 \%)$. The hypercalcemia was correlated with a paraneoplastic syndrome after the exclusion of other diseases.

In humans, paraneoplastic hypercalcemia occurs in up to $10 \%$ of all patients with advanced cancer and is commonly associated with worse prognosis
$[7,15]$. This syndrome was associated with high PTRrP secretion by breast cancer in women [22]. Positive immunohistochemistry expression of PTH-rP was present in $60 \%$ of 102 women with breast tumors, however, serum calcium levels were not increased in these cases [22].

The most common clinical signs of hypercalcemia are nonspecific such as polyuria, polydipsia, anorexia, constipation, lethargy, and weakness $[2,16]$. 
The polyuria caused by hypercalcemia occurs through reduced anti diuretic hormone (ADH) function because of calcium excess. The excess of calcium decreases water reabsorption in the renal tubules and induces compensatory polydipsia [4].

Patients with asymptomatic or mildly symptomatic hypercalcemia (calcium levels $<12 \mathrm{mg} / \mathrm{dL}$ ) do not require immediate treatment [9]. Clinical signs are usually observed with serum calcium levels higher than $15 \mathrm{mg} / \mathrm{dL}$ [2]. However, calcium serum values higher than $18 \mathrm{mg} / \mathrm{dL}$ may trigger seizures, cardiac arrhythmia, acute renal failure and death, being considered a medical emergency $[2,16]$. Most animals of this study presented mild hypercalcemia and that could justify the absence of clinical signs, however the two female dogs with the highest serum calcium levels $(13.43 \mathrm{mg} / \mathrm{dL}$ and $14.28 \mathrm{mg} / \mathrm{dL}$ ) were also asymptomatic.

The main treatment of HM consists of tumor resection $[2,16]$. Other treatments can be performed with fluid containing $0.9 \%$ sodium chloride, furosemide administration in hydrated patients or prednisolone and calcitonin treatment depending on the patient's condition $[15,16]$.

The treatment of the dogs of this study was based only on surgical tumor removal by unilateral mastectomy. The surgery is also the main treatment choice for mammary tumors [3,21].

Hypercalcemia of malignancy was described in a female dog, Teckel, with complex mammary carcinoma. The animal presented $13.9 \mathrm{mg} / \mathrm{dL}$ of serum calcium levels and although normal parathyroid hormone concentration, PTH-related protein concentration was markedly increased. The dog also presented as clinical signs slight lethargy, polyuria and polydipsia and the treatment of HM was based on surgical removal [1].
PTHrP expression was evaluated by immunohistochemistry in eight canine mammary tumors (benign and malignant mixed tumors) and in four animals was observed HM, however in two normocalcemic dogs this protein was present, although the numbers of immunoreactive cells and the immunostaining intensity were lower than hypercalcemic animals [13].

No association between serum calcium levels and clinical-histopathological features were observed in this study. Additionally, there were no correlation between high serum calcium levels and more aggressive tumors and poorer prognosis, conditions evaluated by histological type, tumor grade and clinical stage.

\section{CONCLUSIONS}

The evaluation of serum calcium levels is an important clinical test to be done in female dogs with mammary tumors, besides to be an affordable and technically simple test. The clinical signs related to $\mathrm{HM}$ are nonspecific and may be confused with other diseases commonly observed in older dogs. This study suggest that there are no correlation between serum calcium levels with aggressiveness of canine mammary tumors and with other clinical features.

Funding. This work was supported by Sao Paulo Research Foundation (FAPESP), Grant 2010/13777-5 and 2011/10279-7.

Ethical approval. All procedures were performed under the approval of the Ethics Committee on the Use of Animals (CEUA) of FCAV, UNESP, Jaboticabal, Sao Paulo, Brazil (protocol number 028129/10).

Declaration of interest. The authors report no conflicts of interest. The authors alone are responsible for the content and writing of the paper.

\section{REFERENCES}

1 Bae B.K., Kim C.W., Choi U.S., Choi E.W., Jee H., Kim D.Y. \& Lee C.W. 2007. Hypercalcemia and high parathyroid hormonerelated peptide concentration in a dog with a complex mammary carcinoma. Veterinary Clinical Pathology. 36(4): 376-378.

2 Bergman P.J. 2012. Paraneoplastic hypercalcemia. Topics in Companion Animal Medicine. 27(4): 156-158.

3 Cassali G.D., Lavalle G.E., Ferreira E., Estrela-Lima A., De Nardi A.B., Ghever C., Sobral R.A., Amorim R.L., Oliveira L.O., Sueiro F.A.R., Beserra H.E.O., Bertagnolli A.C., Gamba C.O., Damasceno K.A., Campos C.B., Araujo M.R., Campos L.C., Monteiro L.N., Nunes F.C., Horta R.S., Reis D.C., Luvizotto M.C.R., Magalhães G.M., Raposo J.B., Ferreira A.M.R., Tanaka N.M., Grandi F., Ubukata R., Batschinski K., Terra E.M., Salvador R.C.L., Jark P.C., Delecrodi J.E.R., Nascimento N.A., Silva D.N., Silva L.P., Ferreira K.C.R.S., Frehse M.S., Di Sandis G.W., Silva E.O., Guim T.N., Kerr B., Cintra P.P., Silva F.B.F., Leite J.S., Mello M.F.V., Ferreira M.L.G., Fukumasu H., Salgado B.S. \& Torres R. 2014. Consensus for the diagnosis, prognosis and treatment of canine mammary tumors - 2013. Brazilian Journal of Veterinary Pathology. 7(2): 38-69. 
4 Cohen M. \& Post G.S. 2002. Water transport in the kidney and nephrogenic diabetes insipidus. Journal of Veterinary Internal Medicine. 16(5): 510-517.

5 Elliott J. 1991. Hypercalcemia in the dog: a study of 40 cases. Journal of Small Animal Practice. 32(11): 564-571.

6 Elston C.W. \& Ellis I.O. 1998. Assessment of histological grade. In: Elston C.W. \& Ellis I.O. (Eds). Systemic Pathology - The Breast. 3rd edn. London: Churchill and Livingstone, pp.365-384.

7 Furihata M.J. Sonobe H., Iwata J., Ido E., Ohtsuki Y., Asahi Y., Kubonishi I. \& Miyoshi I. 1996. Lung squamous cell carcinoma producing both parathyroid hormone-related peptide and granulocyte colony stimulating factor. Pathology International. 46(5): 376-379.

8 Gajanayake I., Priestnall S.L., Benigni L., English K., Summers B.A. \& Garden O.A. 2010. Paraneoplastic hypercalcemia in a dog with benign renal angiomyxoma. Journal of Veterinary Diagnostic Investigation. 22(5): 775-780.

9 Groman R.P. 2012. Acute management of calcium disorders. Topics in Companion Animal Medicine. 27(4): 167-171.

10 Hofbauer L.C., Neubauer A. \& Heufelder A.E. 2001. Receptor activator of nuclear factorkappa B ligand and osteoprotegerin: potential implications for the pathogenesis and treatment of malignant bone diseases. Cancer. 92(3): 460-470.

11 Hori Y., Uechi M., Kanakubo K., Sano T. \& Oyamada T. 2006. Canine ovarian serous papillary adenocarcinoma with neoplastic hypercalcemia. Journal of Veterinary Medical Science. 68(9): 979-982.

12 Kleiter M., Hirt R., Kirtz G. \& Day M.J. 2001. Hypercalcaemia associated with chronic lymphocytic leukaemia in a Giant Schnauzer. Australian Veterinary Journal. 79(5): 335-338.

13 Konno A., Sukegawa A., Kusano M., Kariya K., Ishida T. \& Okada H. 2000. Immunohistochemistry for parathyroid hormone-related protein (PTHrP) in benign and malignant mammary mixed tumors of dogs with and without hypercalcemia. Japanese Journal of Veterinary Research. 47(3-4): 155-162.

14 Lane A.E. \& Wyatt K.M. 2012. Paraneoplastic hypercalcemia in a dog with thyroid carcinoma. Canadian Veterinary Journal. 53(10): 1101-1104.

15 Lumachi F., BrunelloA., RomaA. \& Basso U. 2008. Medical treatment of malignancy-associated hypercalcemia. Current Medicinal Chemistry. 15(4): 415-421.

16 Mangieri J. 2009. Síndromes paraneoplásicas. In: Daleck C.R., De Nardi A.B. \& Rodaski S. (Eds). Oncologia em Cães e Gatos. São Paulo: Roca, pp.238-252.

17 Polton G.A. \& Brearley M.J. 2007. Clinical stage, therapy, and prognosis in canine anal sac gland carcinoma. Journal of Veterinary Internal Medicine. 21(2): 274-280.

18 Pressler B.M., Rotstein D.S., Law J.M., Rosol T.J., LeRoy B., Keene B.W. \& Jackson M.W. 2002. Hypercalcemia and high parathyroid hormone-related protein concentration associated with malignant melanoma in a dog. Journal of the American Veterinary Medical Association. 221(2): 263-265.

19 Robat C.S., Cesario L., Gaeta R., Miller M., Schrempp D. \& Chun R. 2013. Clinical features, treatment options, and outcome in dogs with thymoma: 116 cases (1999-2010). Journal of the American Veterinary Medical Association. 243(10): 1448-1454.

20 Rosol T.J., Nagode L.A., Couto C.G., Hammer A.S., Chew D.J., Peterson J.L., Ayl R.D., Steinmeyer C.L. \& Capen C.C. 1992. Parathyroid hormone (PTH)-related protein, $\mathrm{PTH}$, and 1,25-dihydroxyvitamin $\mathrm{D}$ in dogs with cancer-associated hypercalcemia. Endocrinology. 131(3): 1157-1164.

21 Sorenmo K.U., Worley D.R. \& Goldschmidt M.H. 2013. Tumors of the mammary gland. In: Withrow S.J. \& MacEwen E.G. (Eds). Small Animal Clinical Oncology. 5th edn. Philadelphia: Saunders Company, pp.538-547.

22 Southby J., Kissin M.W., Danks J.A., Hayman J.A., Moseley J.M., Henderson M.A., Bennett R.C. \& John Martin T. 1990. Immunohistochemical localization of parathyroid hormone-related protein in human breast cancer. Cancer Research. 50(23): 7710-7716.

23 Weir E.C., Norrdin R.W., Matus R.E., Brooks M.B., Broadus A.E., Mitnick M., Johnston S.D. \& Insogna K.L. 1988. Humoral hypercalcemia of malignancy in canine lymphosarcoma. Endocrinology. 122(2): 602-608.

24 Weller R.E. \& Hoffman W.E. 1992. Renal function in dogs with lymphosarcoma and associated hypercalcemia. Journal of Small Animal Practice. 33(2): 61-66.

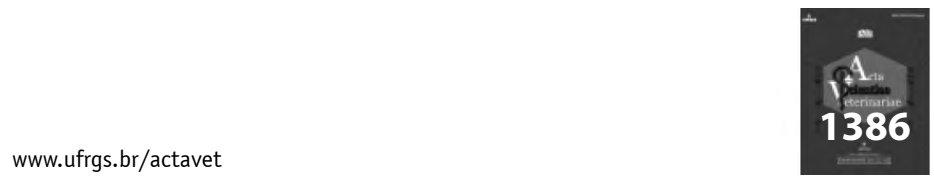

